\title{
Free and Forced Vibration Analysis of an Infilled Steel Frame: Experimental, Numerical, and Analytical Methods
}

\author{
Mohammad Amin Hariri-Ardebili, ${ }^{1}$ Hamid Rahmani Samani, ${ }^{2}$ and Masoud Mirtaheri ${ }^{3}$ \\ ${ }^{1}$ Department of Civil, Environmental and Architectural Engineering, University of Colorado at Boulder (UCB), \\ Boulder, CO 80309-0428, USA \\ ${ }^{2}$ Department of Civil Engineering, Islamic Azad University, Pardis Branch, Tehran 135/16555, Iran \\ ${ }^{3}$ Department of Civil Engineering, K.N. Toosi University of Technology, Tehran, Iran
}

Correspondence should be addressed to Mohammad Amin Hariri-Ardebili; mohammad.haririardebili@colorado.edu

Received 20 February 2014; Revised 27 July 2014; Accepted 7 August 2014; Published 28 August 2014

Academic Editor: Nuno M. Maia

Copyright (c) 2014 Mohammad Amin Hariri-Ardebili et al. This is an open access article distributed under the Creative Commons Attribution License, which permits unrestricted use, distribution, and reproduction in any medium, provided the original work is properly cited.

\begin{abstract}
Structural frames with masonry infill panels make up a significant portion of the buildings constructed in earthquake-prone areas prior to the developing of the seismic design standards. In this paper, the effects of masonry panels on the vibration response of an infilled steel-frame building are investigated. Various ambient and steady state forced vibration tests are carried out to realize the dynamic characteristics of the system. 3D finite element models of the building with and without infill panels are provided based on marcomodeling theorem. A set of analytical approximate formulas are also derived to estimate the vibrational period. The natural frequencies of the building are computed using numerical, analytical, and experimental methods. The results show that neglecting the effect of infill panels leads to considerable error. Moreover, it is shown that there is good agreement among the results obtained by the three methods considering the effect of infill panels.
\end{abstract}

\section{Introduction}

Steel-frame buildings with masonry infill walls are a type of construction widely used throughout many developing countries. Hollow clay tile blocks, hollow concrete blocks, and normal bricks are used in infill walls (Figure 1(a)). The infill walls, being traditionally nonengineered, have as-built properties which at the design stage are almost impossible to estimate reliably and/or to specify and at the construction stage are hard to control [1]. However, the effects of infill walls on the structural properties of a building have been recognized by engineers and studied for a long time [2]. The infill walls are supposed to increase the building stiffness. They also may have some undesirable effects on the building performance, such as enhancing the soft storey mechanism or causing short column effects. Chaker and Cherifati [3] suggested that plane stress finite elements provide a better representation of the in-plane initial stiffness of the infill panels under the small strain condition. In order to simulate the behavior of the infill wall, different types of models can be used [4]: (i) micromodeling in which the effect of mortar joints are considered as a discrete element. In this approach, the brick and mortar are modeled as continuum elements and interface between the brick and mortar is modeled by an interface joint element (Figure 1(b)).

(ii) mesomodeling in which the bricks are modeled by continuum elements, but the mortar joint and its interface with bricks are modeled together as an interface element (Figure 1(c)).

(iii) macromodeling in which a single numerical model represents the infill panel effect [2]. Macromodeling is considered in two levels, that is, (1) homogenized model in which the brick, mortar, and the interface are modeled as one continuum element (Figure 1(d)), and (2) strut model in which the infill panel is modeled by one (Figure 1(e)) or more struts (Figure 1(f)) in each direction.

Micromodeling is relatively time-consuming especially for analysis of large structures [5]. Different mechanisms have 


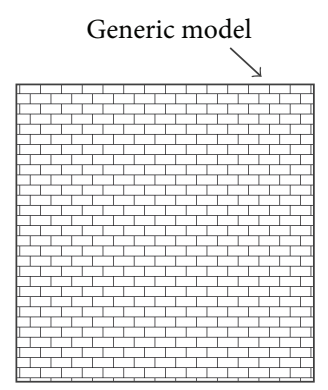

(a)

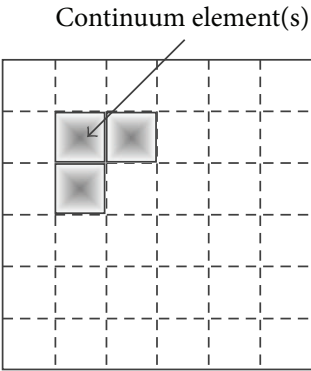

(d)

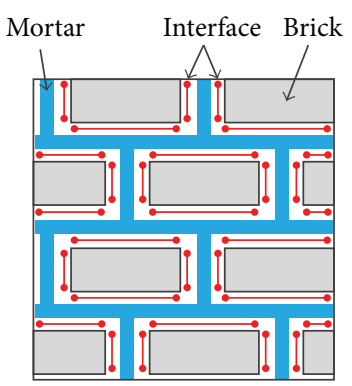

(b)

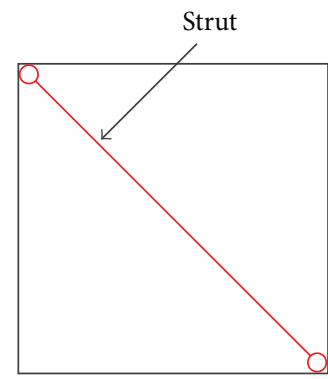

(e)

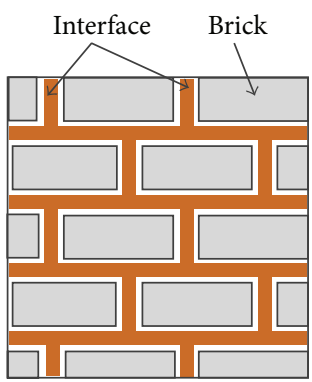

(c)

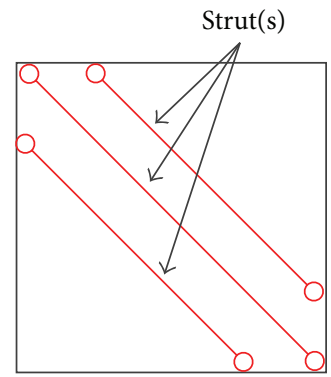

(f)

FIGURE 1: Modeling the masonry infill panels: (a) generic model, (b) micromodeling, (c) mesomodeling, (d) homogenized macromodeling, (e) single-strut macromodeling, and (f) multistrut macromodeling.

been used for the micro- and mesomodeling, for example, nonlinear orthotropic model [6], smeared crack model [7], and dilatant interface constitutive model [8]. The infill panel is macromechanically modeled as homogeneous material and the average properties are used for the whole panel [9]. Modeling the infill panel as an equivalent strut is the most conventional technique. Table 1 summarizes different strut modeling approaches [4]. In addition, all the macro-, mesoand micromodels for simulating the presence of the infill panels are affected by a strong sensitivity to the parameters of the model. Sensitivity and (aleatory and/or epistemic) uncertainty analysis of infilled frames were investigated by Panagiotakos and Fardis [10], Uva et al. [11], Celarec et al. [12], and Celarec and Dolšek [13].

On the other hand the vibrational behavior of the frame structures was investigated by different researchers. Foutch studied the vibrational characteristics of a nine-story reinforcement concrete frame [30]. Jain studied the Imperial County Services Building analytically and compared the response with those recorded by strong motion accelerographs during the 1979 Imperial Valley earthquake [31]. However, the fundamental frequencies from the numerical results and the field measurements were not in close agreement because of the foundation flexibility. Jennings et al. [32] tested a forced vibration experiment on a twenty-two story steelframed structure and extracted first six natural frequencies. Foutch [33] compared the natural frequencies and 3D mode shapes of a twenty story steel structure using forced vibration test and finite element method. He concluded that the properties of the primarily translational modes are predicted reasonably well, but adequate prediction of torsional motions is not obtained. Trifunac [34] compared ambient and forced vibration techniques for testing full-scale structures under small level excitations. He concluded that both methods provide mutually consistent results.

Beside the different experimental and numerical techniques that are used for free and forced vibration analysis of structures, the dynamic behavior of the buildings and towers can be estimated by analytical methods. Free vibration of beam-like structures was studied by several researchers [3537]. Most of the previous studies have been oriented towards the closed-form solutions of the free flexural vibration of a beam. Li et al. [38] derived the exact solution for free flexural vibration of the stepped cantilever beams subjected to axial loads. They used the exact solution of a prismatic beam accompanied by the transfer matrix method. However, effects of the soil-structure interaction (SSI), shear deformation, and the joint flexibility were not considered. Lin and Chang [39] investigated free vibration analysis of a multispan beam with arbitrary number of flexible constraints. They assumed that each span of the continuous beam obeys Timoshenko beam theory. Firouz-Abadi et al. [40] studied the transverse free vibrations of typical truncated nonuniform Euler-Bernoulli beams by using a WKB global approximation. Sina et al. [41] proposed a new beam theory for free vibration analysis of functionally graded beams. The beam properties were assumed to be varied through the thickness following a power law distribution. Also, it was assumed that the lateral normal stress of the beam is zero. Carrera et al. [42] proposed a hierarchical finite element method based on the Carrera Unified Formulation for free vibration analysis of beam with arbitrary section geometries. Ghasemzadeh et al. [43] proposed a set of approximate formulas to determine the natural frequencies of the structures considering the panel zone flexibility and SSI 
TABLE 1: Summary of different strut modeling approaches [4].

\begin{tabular}{|c|c|c|c|}
\hline Model & Researchers, year [Reference] & Number of strut(s) & Modeling outlines \\
\hline 1 & Holmes, $1961[14]$ & One & $\begin{array}{l}\text { Modeling the ultimate strength, stiffness, and deflection } \\
\text { at failure of the infill }\end{array}$ \\
\hline 2 & Stafford-Smith, 1962 [15] & One & Modeling effective width of the equivalent (linear) strut \\
\hline 3 & Stafford-Smith and Carter, 1969 [16] & One & $\begin{array}{l}\text { Modeling stiffness, ultimate strength, and cracking load } \\
\text { of the infill }\end{array}$ \\
\hline 4 & Mainstone and Weeks, 1970 [17] & One & Modeling stiffness and strength of the infill \\
\hline 5 & Mainstone, 1971 [18] & One & Modeling stiffness and strength of the infill \\
\hline 6 & Klingner and Bertero, 1978 [19] & One & $\begin{array}{l}\text { Modeling the hysteretic response, strength and stiffness } \\
\text { of the infill }\end{array}$ \\
\hline 7 & Te-Chang and Kwok-Hung, 1984 [20] & One & Modeling stiffness and strength of the infill \\
\hline 8 & Syrmakezis and Vratsanou, 1986 [21] & Five & $\begin{array}{l}\text { Considering the effect of the contact length on the } \\
\text { moment distribution of the frame as well as strength } \\
\text { and stiffness of the infill }\end{array}$ \\
\hline 9 & Zarnic and Tomazevic, 1988 [22] & One & Modeling the lateral strength and stiffness of the infill \\
\hline 10 & Schmidt, 1989 [23] & Two & $\begin{array}{l}\text { Modeling the frame-infill interaction as well as strength } \\
\text { and stiffness of the infill }\end{array}$ \\
\hline 11 & Chrysostomou, 1991 [24] & Three & $\begin{array}{l}\text { Modeling the frame-infill interaction as well as the } \\
\text { hysteretic seismic response of the infilled frame } \\
\text { considering stiffness and strength degradation }\end{array}$ \\
\hline 12 & Saneinejad and Hobbs, 1995 [25] & One & $\begin{array}{l}\text { Modeling nonlinear force-displacement response of } \\
\text { infill up to the ultimate load }\end{array}$ \\
\hline 13 & Crisafulli, 1997 [26] & Two & $\begin{array}{l}\text { Modeling the frame-infill interaction as well as } \\
\text { accounting for compressive and shear strength of the } \\
\text { infill }\end{array}$ \\
\hline 14 & Flanagan and Bennett, 1999 [27] & One & $\begin{array}{l}\text { Modeling corner crushing strength and stiffness of the } \\
\text { infill }\end{array}$ \\
\hline 15 & El-Dakhakhni et al., 2003 [28] & Three & $\begin{array}{l}\text { Modeling the frame-infill interaction as well as corner } \\
\text { crushing failure mechanism }\end{array}$ \\
\hline 16 & Dolšek and Fajfar, 2008 [29] & One & $\begin{array}{l}\text { Modeling the force-displacement response of the infill } \\
\text { by a tri-linear response, including post-peak response }\end{array}$ \\
\hline
\end{tabular}

effects. Akgöz and Civalek [44] studied vibration response of the nonhomogenous and nonuniform microbeams in conjunction with Bernoulli-Euler beam and modified couple stress theorem. Li et al. [45] derived a closed form solution for free vibration analysis of axially inhomogeneous beams with different end conditions.

In this paper, an old steel building in which the outer frames have been filled by masonry materials is selected as case study. Various steady state forced vibration tests as well as ambient vibration test are carried out for realize the frame's dynamic characteristics. Also, a set of experiments are used to find out the compressive and shear strength of the masonry infill panels. Some approximate formulas are proposed for free vibration analysis of the steel frame, in which the structure is idealized as prismatic cantilever flexural-shear beam. In addition, 3D finite element model of the building is developed and the macromodeling approach is used for simulation of the infill panels. Finally, the natural frequencies resulting from different methods are compared.

\section{Description of the Case Study Building}

The selected structure is a 36-year-old five-story steelframe building located in Tehran, Iran. The outer frames of the building are filled by brick and masonry materials (Figure 2(a)). The dimensions are $40.70 \mathrm{~m} \times 14.70 \mathrm{~m}$. The building is designed according to the Iranian National Building Code (INBC) [46] for a very high seismic zone. The building is located on soil type III (where the average shear wave velocity to a depth of $30 \mathrm{~m}$ would be $180 \mathrm{~m} / \mathrm{s}$ to $360 \mathrm{~m} / \mathrm{s}$ ). The foundation is strip footing with the depth of $80 \mathrm{~cm}$ and the width of $150 \mathrm{~cm}$. The structural system is moment resisting frame in the E-W direction and concentrically braced frame in the N-S direction. A rigid diaphragm can be assumed according to the roof system used in this building. Young's modulus, E, and the Poisson's ratio, $v$, of the material for the main steel frame are $2.1 \mathrm{E} 5 \mathrm{MPa}$ and 0.3 , respectively. Dead load equal to $\mathrm{DL}=650 \mathrm{~kg} / \mathrm{m}^{2}$ for all stories except the roof level $\left(\mathrm{DL}=600 \mathrm{~kg} / \mathrm{m}^{2}\right)$ and live load equal to $\mathrm{LL}$ $=350 \mathrm{~kg} / \mathrm{m}^{2}$ for all stories except the second floor ( $\mathrm{LL}=$ $750 \mathrm{~kg} / \mathrm{m}^{2}$ ) are considered based on the as-built drawings. The typical plan view of the building for all the stories is shown in Figure 2(b).

\section{Experimental Tests}

3.1. Instruments. The generated vibrations in structural system should be recorded using the appropriate instruments for 


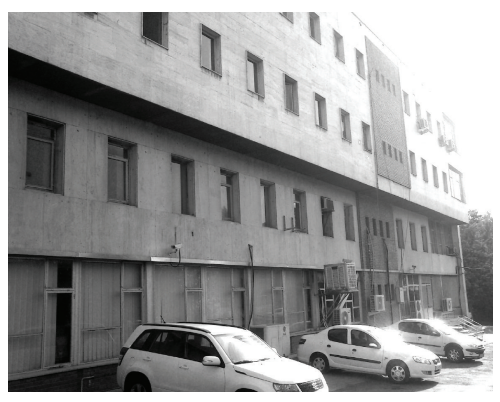

(a)

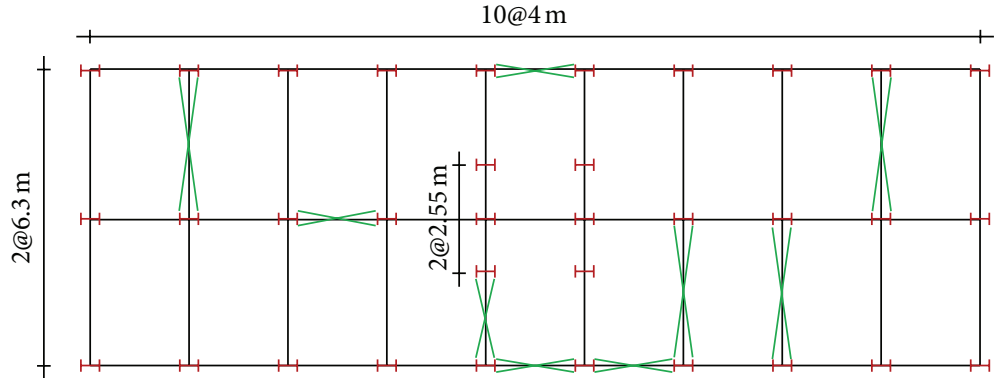

(b)

Figure 2: Case study building: (a) general view, (b) typical plan view.

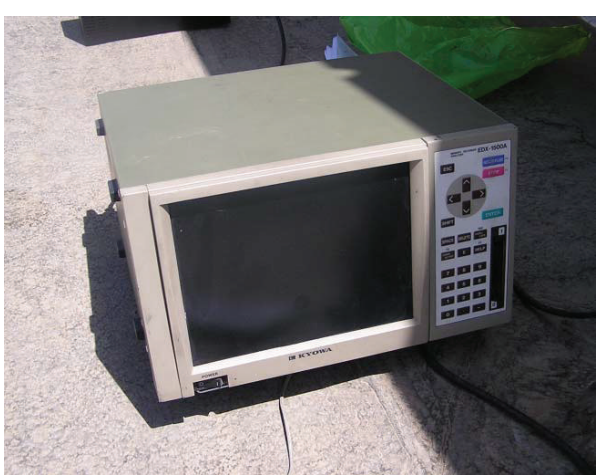

(a)

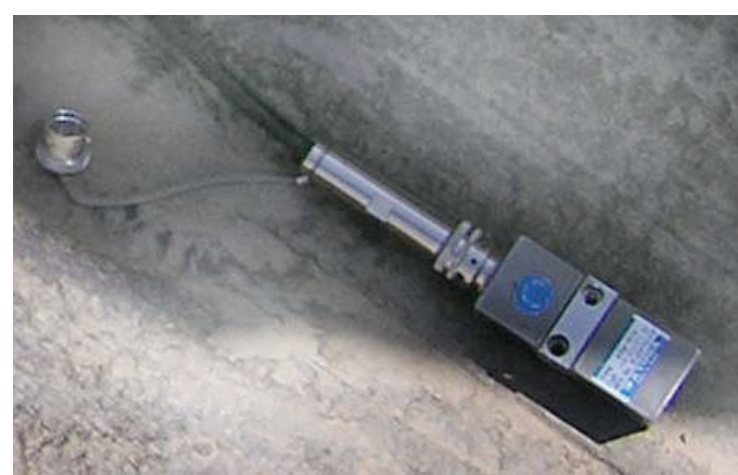

(b)

FIGURE 3: Instruments: (a) data logger, (b) accelerometer.

further analyses. Instruments used for measurement in the present study are data logger and accelerometers (Figure 3 ). EDX-1500A is a sixteen-canal data collector which is able to measure variable frequencies up to $10 \mathrm{KHz}$ (Figure 3(a)). Furthermore, it includes a powerful monitoring system and can be used for revision and process of collected data. EDX$1500 \mathrm{~A}$ includes four signal conditioner cards in which one of them is VAQ-60A and the others are CDV-60A. Each card is used for connecting four accelerometers. CDV-60A card is used just for miniature accelerometers and VAQ-60A card is used just for connection of the server accelerometers. It is noteworthy that all the accelerometers should be calibrated before using in the final measurements. For this purpose VAQ-test is required for ensuring the proper performance of the accelerometers.

There are various methods for shaking of the structure based on purpose of the research. One of the simplest and inexpensive methods is based on the rotation of out of center masses using a motor. For this purpose a shaker was designed by the authors (Figure 4(b)). The shaker basically includes two same mass-points rotating in opposite the directions with the same velocity. Layout and theory of this method are shown in Figure 4(a). As it is clear, the resultant force in this method has a sinusoidal nature just in one direction.

3.2. Steady State Forced Vibration Test. In this test, shaker is installed on the roof of the building approximately near the center of stiffness. In addition, uniaxial accelerometers are installed in all the stories near the center of the stiffness. By shaking the structure in N-S direction and analyzing the recorded data, the natural frequency of building is measured as $\left(\omega_{n}\right)_{\mathrm{N}-\mathrm{S}}=2.70 \mathrm{~Hz}$. By the same method for E-W direction, $\left(\omega_{n}\right)_{\mathrm{E}-\mathrm{W}}=2.50 \mathrm{~Hz}$

The shape of the entire frequency-response wave is controlled by the amount of damping in the system; so it is possible to derive the damping ratio from many different properties of the curve. The most conventional method is bandwidth or half-power method, in which the damping ratio is determined from the frequencies at which the response is $1 / \sqrt{ } 2$ times the peak response. With this method, the damping ratio is computed as about $6 \%$ for this structure.

3.3. Ambient Vibration Test. Considering that all sides of the selected building are free, it is possible to apply ambient vibration test without using any external shaker. For this purpose, data loggers are installed near the center of the stiffness in each story in N-S and E-W directions and results are recorded on a stormy day. Resulting frequencies are the same as those obtained from forced vibration test except that the wind is used as a natural shaker in the ambient vibration test.

\section{Numerical Model}

In this section finite element model of the structure is prepared and the natural frequencies are extracted. For this 


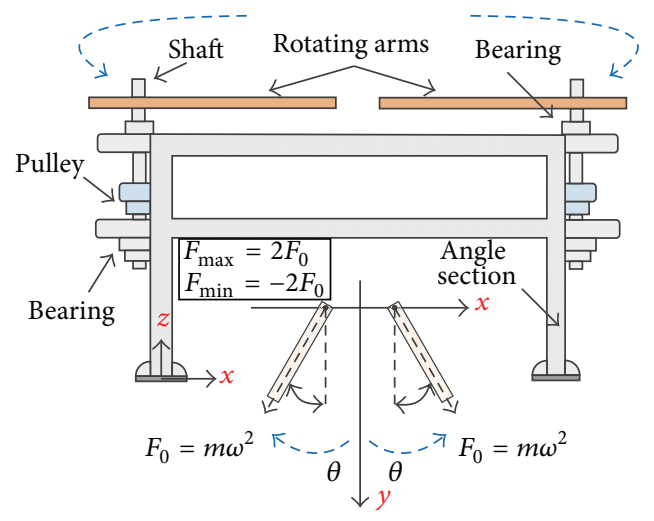

(a)

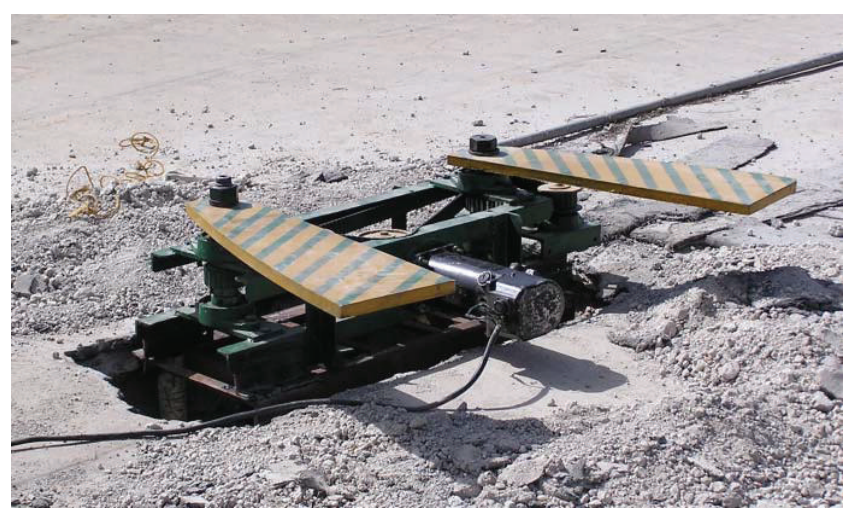

(b)

FIGURE 4: Designed shaker: (a) layout and theory of the shaker, (b) general view under the operation.

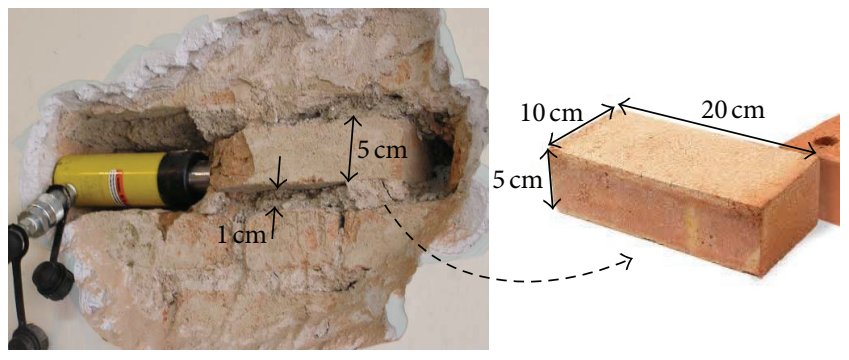

FIGURE 5: Mortar shear stress test on the infill panel.

purpose all the properties of the infill panels should be extracted based on the standard tests.

4.1. Material Properties of Infill Panels. All the infill panels should be in the well condition without any cracking. Then, based on Iranian rehabilitation guideline (2007), chapter 76-1-1-2, shear strength of the mortar should be evaluated as follows [46]: “At least one test is required per $300 \mathrm{~m}^{2}$ of the infill panels. At least 8 tests are required for each building to obtain the reliable results. Moreover, the dispersion of the test locations should be selected in a way that covers all parts of the building". Implementation of this experiment is shown in Figure 5. The mortar average bed-joint shear strength is calculated as

$$
\sigma_{t o}=\frac{V_{\text {test }}}{A_{b}}-\sigma_{c},
$$

where $V_{\text {test }}$ is the load magnitude due to first movement of the masonry unit, $\sigma_{c}$ is the stress due to gravity loads at the test location, and $A_{b}$ is total net area of the bed joints above and below the test unit. The results of the tests and corresponding calculations are summarized in Table 2 . Based on this table, the average shear stress in the mortar is $2.25 \mathrm{~kg} / \mathrm{cm}^{2}$; however, the acceptable value for the mortar shear stress should be calculated using the probabilistic method, chapter 7-6-1-1-2, in a way that $80 \%$ of the test results should have greater value of the final shear stress [47]. Thus, the final value of the mortar shear stress is $1.93 \mathrm{~kg} / \mathrm{cm}^{2}$ in the present case. Considering that the final value is less than $2.0 \mathrm{~kg} / \mathrm{cm}^{2}$, the minimum
TABLE 2: Mortar shear stress of infill panels.

\begin{tabular}{lccc}
\hline Number & $V_{\text {test }} / A_{b}\left(\mathrm{~kg} / \mathrm{cm}^{2}\right)$ & $\sigma_{c}\left(\mathrm{~kg} / \mathrm{cm}^{2}\right)$ & $\sigma_{\text {to }}\left(\mathrm{kg} / \mathrm{cm}^{2}\right)$ \\
\hline V1 & 3.2 & 1.19 & 2.01 \\
V2 & 4.8 & 1.23 & 3.57 \\
V3 & 3.6 & 1.03 & 2.57 \\
V4 & 2.7 & 1.23 & 1.47 \\
V5 & 3.4 & 1.11 & 2.29 \\
V6 & 2.7 & 0.77 & 1.93 \\
V7 & 2.7 & 0.54 & 2.16 \\
V8 & 3.8 & 1.14 & 2.66 \\
\hline Average & & & 2.25 \\
\hline
\end{tabular}

requirements for the mortar strength are not satisfied and there is need for rehabilitation and strengthens.

Based on the conducted tests and considering Iranian rehabilitation guideline [46] and FEMA356 [48] recommendations for calculation of the compressive strength of the mortar, the basic parameters are as follows: brick compressive and tensile strength, $f_{\mathrm{cb}}^{\prime}$ and $f_{\mathrm{tb}}^{\prime}$, are $38.5 \mathrm{~kg} / \mathrm{cm}^{2}$ and $5.5 \mathrm{~kg} / \mathrm{cm}^{2}$, respectively, and the mortar compressive strength, $f_{j}^{\prime}$, is $10.0 \mathrm{~kg} / \mathrm{cm}^{2}$. In addition, the thickness of the brick and the mortar are $h=5.0 \mathrm{~cm}$ and $j=1.0 \mathrm{~cm}$, respectively. Thus, the compressive strength can be calculated as

$$
f_{m}^{\prime}=\frac{f_{\mathrm{cb}}^{\prime}}{1.5} \times \frac{\left((j / 4.1 h) \times f_{j}^{\prime}\right)+f_{\mathrm{tb}}^{\prime}}{((j / 4.1 h)+1) \times f_{\mathrm{tb}}^{\prime}} .
$$

The resulting $f_{m}^{\prime}$ is $26.66 \mathrm{~kg} / \mathrm{cm}^{2}$. Based on the FEMA356 [48], the factor to translate lower-bound masonry properties to the expected strength masonry properties is 1.3. Also, it recommends a factor to translate compressive strength to the modules of elasticity. The final value for the compressive strength and the modulus of elasticity are $34.658 \mathrm{~kg} / \mathrm{cm}^{2}$ and $19061 \mathrm{~kg} / \mathrm{cm}^{2}$, respectively.

4.2. Developing Macromodels. As mentioned before, there are various methods in order to simulate the infill panels' effects. 


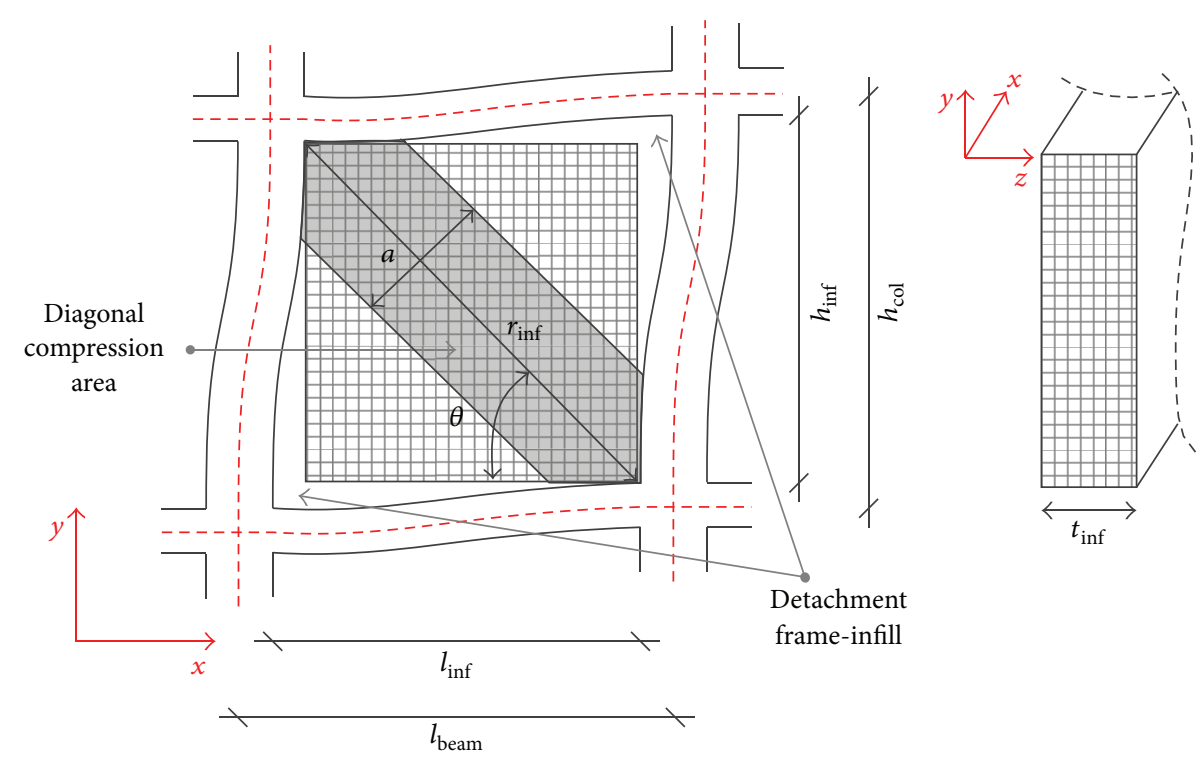

FIGURE 6: Macromodeling of the infill panel based on the equivalent strut approach.

In the present study, both the macromodeling based on continuum elements (Figure 1(d)), and the compressive-strut element (Figure 1(e)) are used. All the beams and columns are modeled using "Beam" elements while all the beamcolumn connections are assumed to be rigid. SSI effect is considered by modeling the foundation and its surrounding environment as massless medium using "Solid" elements. The massless foundation is extended about three times of the building height in all directions. It should be noticed that there is no need to apply the nonreflecting boundary conditions on the far-end boundaries of the foundation model, because no seismic analysis is performed in this paper. In the macromodeling based on the continuum elements, the infill panel is directly modeled by 3D "Shell" elements considering appropriate properties of the main panel. In the macromodeling based on equivalent strut approach, the infill panel is replaced with a diagonal compressive-strut element of width, $a$, and the same thickness and modulus of elasticity of infill panel using "Link" elements. This is a two-node pinned-end element which connects two opposite corners of the frame. The element is capable of transferring only compressive pressure in the axial direction. In this method, the equivalent width, $a$, for the elastic in-plane behavior prior to cracking can be calculated based on Figure 6 [46]:

$$
a=0.175\left[\lambda_{1} h_{\mathrm{col}}\right]^{-0.4} r_{\mathrm{inf}},
$$

where

$$
\lambda_{1}=\left[\frac{E_{\mathrm{me}} t_{\mathrm{inf}} \sin 2 \theta}{4 E_{\mathrm{fe}} I_{\mathrm{col}} h_{\mathrm{inf}}}\right]^{0.25}
$$

in which $h_{\text {col }}$ is the column height between centerlines of beams, $h_{\text {inf }}$ is the height of infill panel, $E_{\mathrm{fe}}$ is the expected modulus of elasticity of frame material, $E_{\text {me }}$ is the expected modulus of elasticity of infill material, $I_{\text {col }}$ is the moment of inertia of column, $r_{\text {inf }}$ is the diagonal length of infill panel, $t_{\text {inf }}$ is the thickness of infill panel and equivalent strut, $\theta$ is the angle whose tangent is the infill height-to-length aspect ratio, and $\lambda_{1}$ is the coefficient used to determine the equivalent width of the strut.

Consequently, three different models are provided in this study for simulation of the building.

(i) The structure is modeled without infill panels effects (reference case)

(ii) The structure is modeled considering the infill panels as a compressive struts

(iii) The structure is modeled considering the infill panels as $3 \mathrm{D}$ shell elements.

\section{Analytical Approximate Solution}

5.1. Fundamentals and Assumptions. In order to derive a set of appropriate approximate formulas for analytical vibration analysis of the structure, a doubly symmetric structure in plan is selected as a sample which is subjected to uniformly distributed gravity loads at story levels as shown in Figure 7(a). It is also assumed that both the beams and the columns have uniform sections throughout the height of the building. Furthermore, floor slabs are considered as rigid diaphragms in their own plane so that the relative displacements between frames are restricted.

The structure is idealized as a prismatic cantilever beam with flexural rigidity $E I$, shear rigidity $G A$, axial distributed compression force $N$, and mass per unit length $m$, as shown in Figure 7(b). Floor masses and gravity loads at story levels are also replaced by concentrated masses $m_{i}$ and concentrated forces $N_{i}$, respectively. SSI is modeled using the axial and torsional springs. The general algorithm for the analytical solution is summarized in Figure 8 and will be explained in detail in the next subsections. 


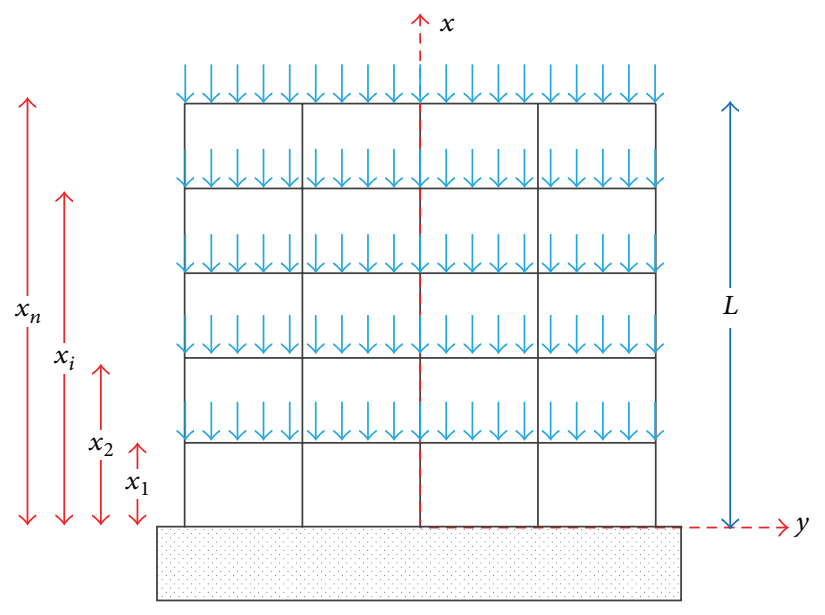

(a)

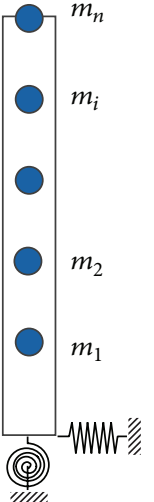

(1)

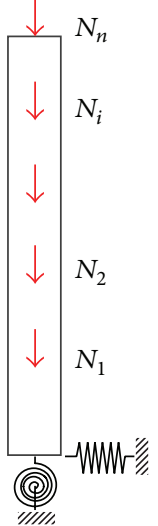

(b)

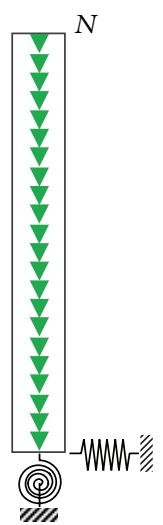

III

FIgURE 7: Analytical model: (a) schematic drawing of a doubly symmetric structure, (b) equivalent beam model of the structure.

\subsection{Concept of Energy Method}

5.2.1. Kinetic and Potential Energy. Assuming that the frame is vibrating freely, the kinetic energy $T$ is given by [43]:

$$
T=\frac{1}{2} \int_{0}^{L} m \dot{u}(x, t)^{2} d x+\frac{1}{2} \sum_{i=1}^{n} m_{i} \dot{u}\left(x_{i}, t\right)^{2}
$$

in which $u(x, t)$ is transverse displacement of the frame, dots indicate the differentiation with respect to time $t, n$ is the total number of stories, and $L$ is the height of the structure. The transverse displacement of the structure is expressed as

$$
u(x, t)=\underbrace{u_{f}(x, t)+u_{\mathrm{sh}}(x, t)}_{u_{\mathrm{B}}(x, t)}+\underbrace{u_{a}(x, t)+u_{r}(x, t)}_{u_{S}(x, t)},
$$

where $u_{B}$ and $u_{S}$ are contribution of beam (frame) and springs (soil) in the lateral displacement, respectively, $u_{f}$ is portion of the displacement induced by bending deformation and $u_{\mathrm{sh}}$ is portion of the displacement induced by the shear deformation of the beam. $u_{a}$ is transverse displacement due to foundation sliding and $u_{r}$ is transverse displacement due to foundation rotation.

The potential energy of the system, $\Pi$, consists of the strain energy, $U$, and the work done by external loads, $V$ :

$$
\Pi=U+V,
$$

where

$$
\begin{aligned}
U= & \frac{1}{2} \int_{0}^{L} E I\left[u_{f}^{\prime \prime}(x, t)\right]^{2} d x \\
& +\frac{1}{2} \int_{0}^{L} \frac{G A}{\mu}\left[u_{\mathrm{sh}}^{\prime}(x, t)\right]^{2} d x \\
& +\frac{1}{2} K_{a}\left[u_{a}(x, t)\right]^{2}+\frac{1}{2} K_{r}\left[\theta_{r}(t)\right]^{2},
\end{aligned}
$$

where $\mu$ is the shear shape factor of the cross-section, considering the effects of uneven distribution of shear deformation over the cross-section, $K_{a}$ is the stiffness coefficient against sliding of the foundation, $K_{r}$ is the stiffness coefficient against rotation of the foundation, and $\theta_{r}$ is rotation of the torsional spring. Consider

$$
V=-\frac{1}{2} \int_{0}^{L} N v(x, t) d x-\frac{1}{2} \sum_{i=1}^{n} N_{i} v\left(x_{i}, t\right)
$$

in which $v(x, t)$ represents the axial shortening due to lateral deformation and is expressed as

$$
v(x, t)=\frac{1}{2} \int\left[u^{\prime}(x, t)\right]^{2} d x .
$$

5.2.2. Energy Equation. Assuming that the structure is vibrating freely in simple harmonic motion, the transverse displacement $u(x, t)$ and the velocity of vibration $\dot{u}(x, t)$ are expressed as

$$
\begin{aligned}
& u(x, t)=u(x) \sin \omega t, \\
& \dot{u}(x, t)=\omega u(x) \cos \omega t,
\end{aligned}
$$

where $\omega$ is the natural vibration frequency. The maximum potential energy of the system over a vibration cycle is associated with the maximum displacement; that is,

$$
\begin{aligned}
\Pi_{\max }=\frac{1}{2}\left[\int_{0}^{L} E I\left[u_{f}^{\prime \prime}(x)\right]^{2} d x\right. \\
+\int_{0}^{L} \frac{G A}{\mu}\left[u_{\mathrm{sh}}^{\prime}(x)\right]^{2} d x+K_{a} u_{a}^{2}+K_{r} \theta_{r}^{2} \\
\left.-\int_{0}^{L} N v(x) d x-\sum_{i=1}^{n} N_{i} v\left(x_{i}\right)\right]
\end{aligned}
$$




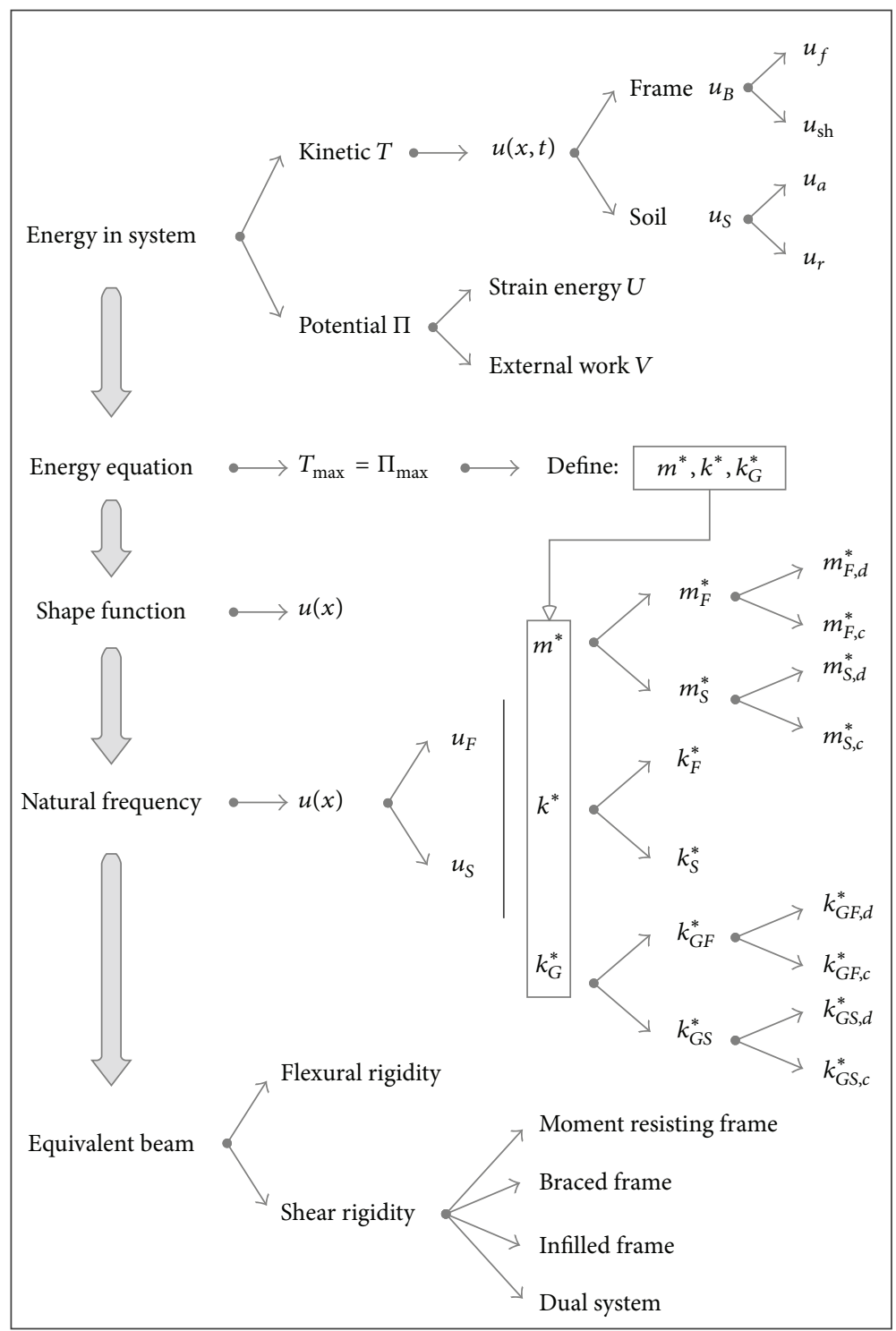

FIGURE 8: Proposed algorithm for analytical vibration analysis of the structure.

and also the maximum kinetic energy of the system over a vibration cycle is associated with maximum velocity:

$$
T_{\max }=\frac{1}{2} \omega^{2}\left[\int_{0}^{L} m[u(x)]^{2} d x+\sum_{i=1}^{n} m_{i}\left[u\left(x_{i}\right)\right]^{2}\right] .
$$

The principle of energy conservation states that the total energy in a freely vibrating system without damping is constant; thus, $T_{\max }$ must be equal to $\Pi_{\max }$ which yields

$$
\omega^{2}=\frac{k^{*}-k_{G}^{*}}{m^{*}}
$$

where

$$
\begin{aligned}
m^{*}= & \int_{0}^{L} m[u(x)]^{2} d x+\sum_{i=1}^{n} m_{i}\left[u\left(x_{i}\right)\right]^{2}, \\
k^{*}= & \int_{0}^{L} E I\left[u_{f}^{\prime \prime}(x)\right]^{2} d x \\
& +\int_{0}^{L} \frac{G A}{\mu}\left[u_{\mathrm{sh}}^{\prime}\right]^{2} d x+K_{a} u_{a}^{2}+K_{r} \theta_{r}^{2}, \\
k_{G}^{*}= & \int_{0}^{L}\left(N \int\left[u^{\prime}(x)\right]^{2} d x\right) d x+\sum_{i=1}^{n} N_{i} \int\left[u^{\prime}\left(x_{i}\right)\right]^{2} d x .
\end{aligned}
$$

As seen, (14) is of the same form as the frequency expression for a single degree of freedom (SDOF) system. In other words, by restricting the lateral displacement of the structure to a single shape function, $u(x)$, which defines the mode shape, the structure behaves as a generalized SDOF system [47]. 
Parameters $m^{*}$ and $k^{*}$ are generalized mass and generalized stiffness of the system, respectively, and $k_{G}^{*}$ is generalized geometric stiffness of the system which considers the effect of axial loads on the natural frequency. Assuming that all the stories have equal height of $h_{s}$, all floor slabs have equal mass of $m_{0}$, and gravity loads at story levels are equal to $N_{0}$. Thus, (15) can be simplified as

$$
\begin{aligned}
m^{*} & =\int_{0}^{L} m[u(x)]^{2} d x+m_{0} \sum_{i=1}^{L / h_{s}} u^{2}\left(x_{i}\right), \\
k_{G}^{*} & =\int_{0}^{L}\left(N \int\left[u^{\prime}(x)\right]^{2} d x\right) d x+N_{0} \sum_{i=1}^{L / h_{s}} \int_{0}^{i h_{s}}\left[u^{\prime}\left(x_{i}\right)\right]^{2} d x .
\end{aligned}
$$

5.2.3. Proper Shape Function. The accuracy of frequency of vibration depends on the assumed shape function, $u(x)$. The more accurate the shape function is, the more accurate the result would be. It is worth mentioning that $u(x)$ is not a particular function, and any shape function satisfying the geometric boundary conditions can be used. By using the deflected shape of the equivalent beam due to a selected set of forces, the geometric boundary conditions are automatically satisfied. Several methods are available to determine the deflected shape of the structure, but arguably, the most promising one is the principle of virtual work:

$$
u(x)=\int \frac{M m_{v}}{E I} d x+\int \mu \frac{Q q}{G A}+\frac{M_{b} m_{b}}{K_{\varphi}}+\frac{Q_{b} q_{b}}{K_{s}}
$$

where $Q$ and $M$ are the real shear and moment functions along the length of the structure, respectively, and $q$ and $m_{v}$ are the virtual force functions in the structure arising from the application of unit load. $Q_{b}$ and $M_{b}$ are the real shear and moment at the base of the structure, respectively, and finally $q_{b}$ and $m_{b}$ are the virtual forces at the base of the structure from the application of unit load, respectively.

5.3. Calculation of the Natural Frequency. Considering the SSI effects, the deflected shape of the structure, $u(x)$, under lateral uniform distributed load can be written as

$$
u(x)=\underbrace{u_{f}+u_{\mathrm{sh}}}_{u_{F}}+u_{S}
$$

where

$$
\begin{aligned}
& u_{F}=\frac{P}{2 E I}\left(-\frac{L}{3} x^{3}+\frac{L^{2}}{2} x^{2}+\frac{x^{4}}{12}\right)+\frac{\mu P}{G A}\left(L x-\frac{x^{2}}{2}\right), \\
& u_{S}=\frac{P L}{K_{a}}+\frac{P L^{2}}{2 K_{r}} x .
\end{aligned}
$$

The subscript, $F$, represents the fixity of the lowermost elevation and subscript, $S$, represents the effects of soil flexibility. Using (14) for extracting the natural frequencies in the present case, new parameters can be derived as follows:

$$
\begin{aligned}
m^{*} & =\underbrace{m_{F, d}^{*}+m_{F, c}^{*}}_{m_{F}^{*}}+\underbrace{m_{S, d}^{*}+m_{S, c}^{*}}_{m_{S}^{*}}, \\
k_{G}^{*} & =\underbrace{k_{G F, d}^{*}+k_{G F, c}^{*}}_{k_{G F}^{*}}+\underbrace{k_{G S, d}^{*}+k_{G S, c}^{*}}_{k_{G S}^{*}}, \\
k^{*} & =k_{F}^{*}+k_{S}^{*} .
\end{aligned}
$$

Different terms are defined as follows in which the subscripts $d$ and $c$ represent the portions associated with distributed axial load and concentrated axial forces, respectively:

$$
\begin{aligned}
& m_{F, d}^{*}=m\left(\frac{2}{15} \frac{\mu^{2} n^{5} h_{s}^{5}}{(G A)^{2}}+\frac{37}{840} \mu \frac{n^{7} h_{s}^{7}}{G A E I}+\frac{13}{3240} \frac{n^{9} h_{s}^{9}}{(E I)^{2}}\right), \\
& m_{F, c}^{*}=m_{0}\left(\frac{1}{120} \mu^{2} n h_{s}^{4} \frac{\left(16 n^{4}+15 n^{3}-1\right)}{(G A)^{2}}+\frac{1}{5040}\right. \\
& \times \mu n h_{s}^{6} \frac{\left(222 n^{6}+315 n^{5}+70 n^{4}+28 n^{2}-5\right)}{G A \times E I} \\
& +\frac{1}{51840} \\
& \left.\times n h_{s}^{8} \frac{\left(208 n^{8}+405 n^{7}+180 n^{6}+20 n^{2}-3\right)}{(E I)^{2}}\right), \\
& m_{S, d}^{*}=m\left(\frac{1}{12} \frac{n^{7} h_{s}^{7}}{K_{r}^{2}}+\frac{13}{360} \frac{n^{8} h_{s}^{8}}{E I K_{r}}+\frac{5}{24} \mu \frac{n^{6} h_{s}^{6}}{G A K_{r}}\right. \\
& \left.+\frac{n^{3} h_{s}^{3}}{K_{a}^{2}}+\frac{1}{10} \frac{n^{6} h_{s}^{6}}{E I K_{a}}+\frac{2}{3} \mu \frac{n^{4} h_{s}^{4}}{G A K_{a}}+\frac{1}{2} \frac{n^{5} h_{s}^{5}}{K_{r} K_{a}}\right), \\
& m_{S, c}^{*}=m_{0}\left(\frac{1}{24} n^{5} h_{s}^{6} \frac{\left(2 n^{2}+3 n+1\right)}{K_{r}^{2}}\right. \\
& +\frac{n^{3} h_{s}^{2}}{K_{a}^{2}}+\frac{1}{2} \frac{h_{s}^{4}\left(n^{5}+n^{4}\right)}{K_{a} K_{r}} \\
& +\frac{1}{1440} n^{4} h_{s}^{7} \frac{\left(52 n^{4}+90 n^{3}+35 n^{2}+3\right)}{E I K_{r}} \\
& +\frac{1}{24} n^{4} h_{s}^{5} \mu \frac{\left(5 n^{2}+6 n+1\right)}{G A K_{r}} \\
& +\frac{1}{360} n^{2} h_{s}^{5} \frac{36 n^{4}+45 n^{3}+9 n^{2}-1}{E I K_{a}} \\
& \left.+\frac{1}{6} n^{2} h_{s}^{3} \mu \frac{4 n^{2}+3 n-1}{G A K_{a}}\right),
\end{aligned}
$$




$$
\begin{aligned}
& k_{G F, d}^{*}= N\left(\frac{1}{4} \mu^{2} \frac{n^{4} h_{s}^{4}}{(G A)^{2}}+\frac{1}{18} \mu \frac{n^{6} h_{s}^{6}}{G A \times E I}+\frac{1}{160} \frac{n^{8} h_{s}^{8}}{(E I)^{2}}\right), \\
& k_{G F, c}^{*}= N_{0}\left(\frac{1}{12} \mu^{2} n^{2} h_{s}^{3} \frac{\left(3 n^{2}+2 n-1\right)}{(G A)^{2}}+\frac{1}{180}\right. \\
& \times \mu n^{2} h_{s}^{5} \frac{\left(10 n^{4}+9 n^{3}-1\right)}{G A \times E I}+\frac{1}{30,240} n^{2} h_{s}^{7} \\
&\left.\times \frac{\left(189 n^{6}+270 n^{5}+70 n^{4}+21 n^{2}-10\right)}{(E I)^{2}}\right), \\
& k_{G S, c}^{*}= N\left(\frac{1}{3} \mu \frac{n^{5} h_{s}^{5}}{G A K_{r}}+\frac{1}{20} \frac{n^{7} h_{s}^{7}}{E I K_{r}}+\frac{1}{8} \frac{n^{6} h_{s}^{6}}{K_{r}^{2}}\right) \\
& k_{G S, d}^{*}= N_{0}\left(\frac{1}{720} n^{3} h_{s}^{6} \frac{\left(36 n^{4}+45 n^{3}+10 n^{2}-1\right)}{E I K_{r}}\right. \\
& k_{S}^{*}=\left.\frac{L^{2}}{K_{a}}+\frac{L^{4}}{4 K_{r}} \cdot \frac{1}{12} \mu n^{3} h_{s}^{4} \frac{4 n^{4}+3 n-1}{G A K_{r}}+\frac{1}{8} h_{s}^{5} \frac{n^{6}+n^{5}}{K_{r}^{2}}\right), \\
& k_{F}^{*}=\frac{n^{5} h_{s}^{5}}{20 E I}+\mu \frac{n^{3} h_{s}^{3}}{3 G A},
\end{aligned}
$$

\subsection{Properties of Equivalent Beam}

5.4.1. Flexural Rigidity. The modulus of elasticity, $E$, for the equivalent beam should be the same as the modulus of elasticity of the real structure. The moment of inertia, $I$, of the equivalent beam is

$$
\begin{aligned}
& I_{z}=\sum A_{c i}\left(y_{i}\right)^{2}, \\
& I_{y}=\sum A_{c i}\left(z_{i}\right)^{2}
\end{aligned}
$$

in which $A_{c i}$ is the cross-sectional area of the ith column, $y_{i}$ is the distance of the $i$ th column from $z$ axis, and $z_{i}$ is the distance of the $i$ th column from $y$ axis.

\subsubsection{Shear Rigidity}

(1) Moment Resisting Frame. In order to calculate the shear rigidity per unit web frame, $G A / \mu$, a subassemblage is extracted from the frame assuming that inflection points occur at midspan of the beams on either side of the joint and at midheight of the columns above and below the joint. This subassemblage is shown in Figure 9. It is further assumed that the beams on either side of the joint are of the same section and length and that the columns above and below the joint are the same section and length. $G A / \mu$ is obtained by equalizing the displacement of the subassemblage to displacement of a

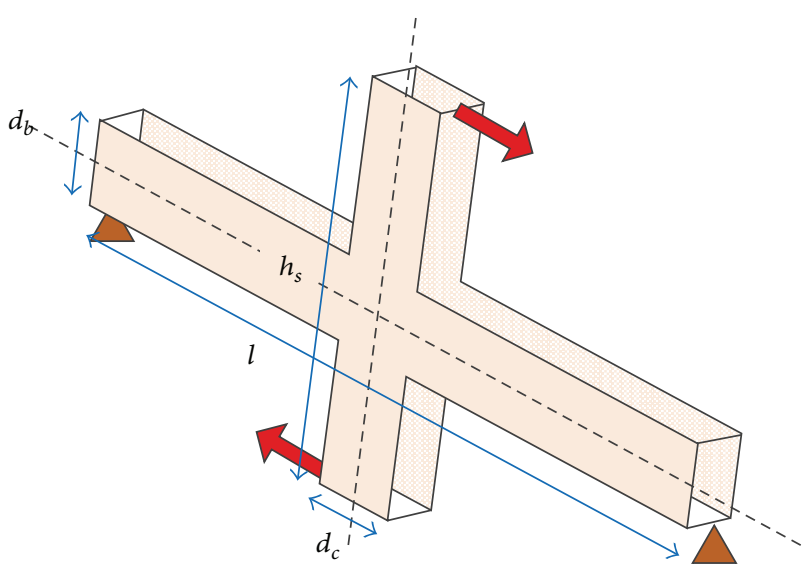

FIGURE 9: Subassemblage for calculation of the shear rigidity.

shear element. Considering completely rigid joints, the shear rigidity is computed as follows:

$$
\left(\frac{G A}{\mu}\right)_{\text {frame }}=\frac{E h_{s}}{S_{d}}
$$

where

$$
\begin{aligned}
S_{d}= & \frac{\left(l-d_{c}\right)^{3}}{12 I_{b}} \frac{h_{s}^{2}}{l^{2}}+\frac{\left(h_{s}-d_{b}\right)^{3}}{12 I_{c}} \\
& +\frac{E}{G}\left[\frac{\left(l-d_{c}\right)}{A_{b}} \frac{h_{s}^{2}}{l^{2}}+\frac{\left(h_{s}-d_{b}\right)}{A_{c}}\right]
\end{aligned}
$$

in which $h_{s}$ is the height of column (story height), $l$ is the length of the beam (bay width), $d_{b}$ and $d_{c}$ are depth of the beam and depth of the column, respectively, $I_{b}$ and $I_{c}$ are moment of inertia of the beam and the column, respectively, and $A_{b}$ and $A_{c}$ are cross-sectional area of the beam and the column, respectively.

(2) Braced Frame. The equivalent shear rigidity of double bracings is

$$
\left(\frac{G A}{\mu}\right)_{\text {brace }}=2 A_{\mathrm{br}} E_{\mathrm{br}} \frac{l}{l^{2}+h_{s}^{2}},
$$

where $A_{\mathrm{br}}$ and $E_{\mathrm{br}}$ are the cross-sectional area and Young's modulus of the brace, respectively. For a single and tensiononly bracing, the coefficient 2 in (25) must be replaced with 1.

(3) Infilled Frame. In order to consider the effect of infill panel, shear rigidity of the infill panel should be added to the equivalent shear rigidity of the system:

$$
\left(\frac{G A}{\mu}\right)_{\text {infilled frame }}=\left(\frac{G A}{\mu}\right)_{\text {frame }}+\left(\frac{G A}{\mu}\right)_{\text {infill panel }} .
$$

(4) Dual System. The equivalent shear rigidity of the dual system is

$$
\left(\frac{G A}{\mu}\right)_{\text {dual system }}=\left(\frac{G A}{\mu}\right)_{\text {frame }}+\left(\frac{G A}{\mu}\right)_{\text {brace }} .
$$




\section{Results}

In this section, the results obtained from numerical simulations, experimental tests, analytical approximate formulas, and the codified proposed values for natural frequencies are compared. Table 3 summarizes all the methods used in this study and also the corresponding abbreviations. Based on this table, two experimental methods, six numerical models with and without infill panel effect on rigid/flexible foundation, four analytical approximate formulations, and finally three codified-based methods are used in order to estimate the natural frequencies.

Figure 10 shows the natural frequencies of the considered building in N-S and E-W directions using various methods. As mentioned before, the results of the natural frequencies based on forced vibration and ambient vibration tests have the same values and are $2.70 \mathrm{~Hz}$ in N-S and $2.50 \mathrm{~Hz}$ in E-W directions. Based on the numerical models, it can be concluded that neglecting infill panel effect leads to decreasing the frequency meaningfully. Also, modeling the foundation as a rigid medium leads to increasing the frequency a little in all models. Modeling infill panel as a compressive strut increases frequencies in both directions. The differences between $\mathrm{N} 3$ and $\mathrm{T} 1$ are about $11 \%$ for N-S direction and 10\% in E-W direction. Macromodeling based on shell elements increases the natural frequencies than to macromodeling based on the compressive-strut theorem. In this condition, the differences between N5 and the experimental tests are $5.6 \%$ and $6 \%$ for N-S and E-W directions, respectively. As seen, modeling the infill panel based on the continuum element theorem leads to realistic behavior than to modeling it as a compressive strut.

Table 4 summarizes the percentage of the error between the numerical, approximate formulas, and the codified based methods with the exact values obtained from the experimental tests. Using the proposed approximate formulas neglecting the infill panels leads to almost the same results as those obtained from numerical simulations. On the other hand, using the proposed technique considering both infill panel and SSI effects leads to very close results to the experimental test. In this condition, the percentage of the errors between F4 and $\mathrm{T} 1$ are only $1.5 \%$ and $2.4 \%$ for N-S and E-W directions, respectively. Once again, it should be mentioned that the proposed formulation does not account for the torsional deformation effect. That means that the term GJ/l is not incorporated in the formulas. Therefore, when a building is unsymmetrical, the error of the formula is meaningful. The value of the error depends to the distance between the center of mass and the center of rigidity.

Finally, the results of the experimental tests are compared with codified proposed formulas. All three design codes are proposed an empirical formulation in the form of $T=C \times$ $H^{\beta}$, in which $H$ is the height of the structure and $C$ and $\beta$ are the constant values which differ by the type of the lateral resisting system. Considering that the lateral resisting system in the current case is a combination of moment resisting and braced and infill panel systems, the value of $C$ is 0.05 based on INBC and 0.0488 based on UBC and ASCE [48] codes. The value of the $\beta$ is 0.75 based on all three codes (all
TABLE 3: Different methods/models for frequency analysis.

\begin{tabular}{ll}
\hline Abbreviation & Description \\
\hline T1 & Steady state forced vibration test \\
T2 & Ambient vibration test \\
N1 & Numerical model, without infill panel + SSI \\
N2 & $\begin{array}{l}\text { Numerical model, without infill panel + rigid } \\
\text { foundation }\end{array}$ \\
N3 & $\begin{array}{l}\text { Numerical model, with infill panel (compressive } \\
\text { strut) + SSI }\end{array}$ \\
N4 & $\begin{array}{l}\text { Numerical model, with infill panel (compressive } \\
\text { strut) + rigid foundation }\end{array}$ \\
N5 & Numerical model, with infill panel (shell element) \\
+ SSI & Numerical model, with infill panel (shell element) \\
N6 & + rigid foundation \\
F1 & $\begin{array}{l}\text { Analytical formula, without infill panel + rigid } \\
\text { foundation }\end{array}$ \\
F2 & $\begin{array}{l}\text { Analytical formula, without infill panel + SSI } \\
\text { Analytical formula, with infill panel + rigid } \\
\text { foundation } \\
\text { F3 }\end{array}$ \\
F4 & $\begin{array}{l}\text { Analytical formula, with infill panel + SSI } \\
\text { Codified, based on INBC } \\
\text { Codified, based on UBC } \\
\text { C2 }\end{array}$ \\
C3 & Codified, based on ASCE \\
\hline
\end{tabular}

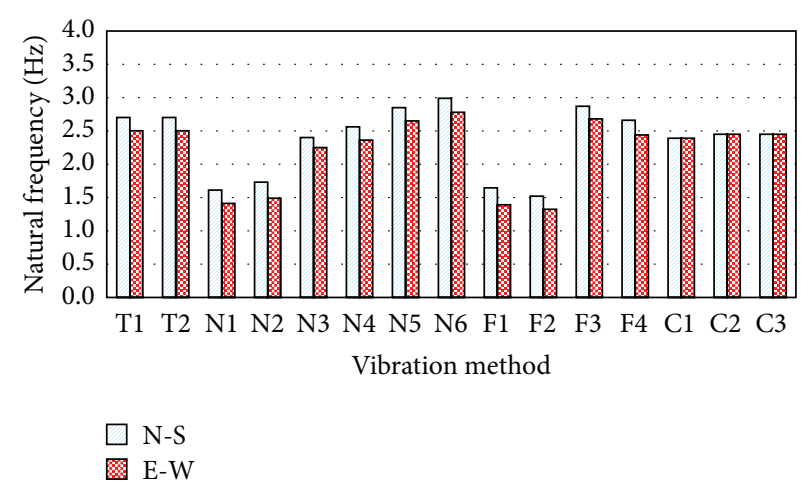

FIGURE 10: Natural frequencies of the building in two orthogonal directions.

values are presented in SI system). Using the codified-based method leads to the same frequency for both directions of the building because this method does not directly account for the direction. Also, it seems that using UBC and ASCE methods leads to a little better result in comparison with INBC.

Figure 11 shows the first mode shape of the considered building in two orthogonal directions using experimental test and numerical models. These mode shapes are extracted based on the relative lateral displacements of the structure in numerical models and also values of the resonance test which describe average peak of Fourier spectrum in different stories. As seen, in both directions N5 model has the closest mode shape to the actual mode shape of building and N1 model has the least similarity to the real mode shape. 
TABLE 4: Percentage of the errors between numerical, analytical, and codified methods with experimental tests.

\begin{tabular}{lccccccccccccc}
\hline \multirow{2}{*}{ Direction } & \multicolumn{4}{c}{ Numerical methods } & \multicolumn{4}{c}{ Approximate formulas } & \multicolumn{4}{c}{ Codified-based methods } \\
& $\mathrm{N} 1$ & $\mathrm{~N} 2$ & $\mathrm{~N} 3$ & $\mathrm{~N} 4$ & $\mathrm{~N} 5$ & $\mathrm{~N} 6$ & $\mathrm{~F} 1$ & $\mathrm{~F} 2$ & $\mathrm{~F} 3$ & $\mathrm{~F} 4$ & $\mathrm{C} 1$ & $\mathrm{C} 2$ & $\mathrm{C} 3$ \\
\hline $\mathrm{N}-\mathrm{S}$ & $40 \%$ & $36 \%$ & $11 \%$ & $5 \%$ & $5.5 \%$ & $10.7 \%$ & $39 \%$ & $44 \%$ & $6.3 \%$ & $1.5 \%$ & $11.5 \%$ & $9.3 \%$ & $9.3 \%$ \\
$\mathrm{E}-\mathrm{W}$ & $44 \%$ & $40 \%$ & $10 \%$ & $5.6 \%$ & $6 \%$ & $11.2 \%$ & $44 \%$ & $47 \%$ & $7.2 \%$ & $2.4 \%$ & $4.4 \%$ & $2 \%$ & $2 \%$ \\
\hline
\end{tabular}

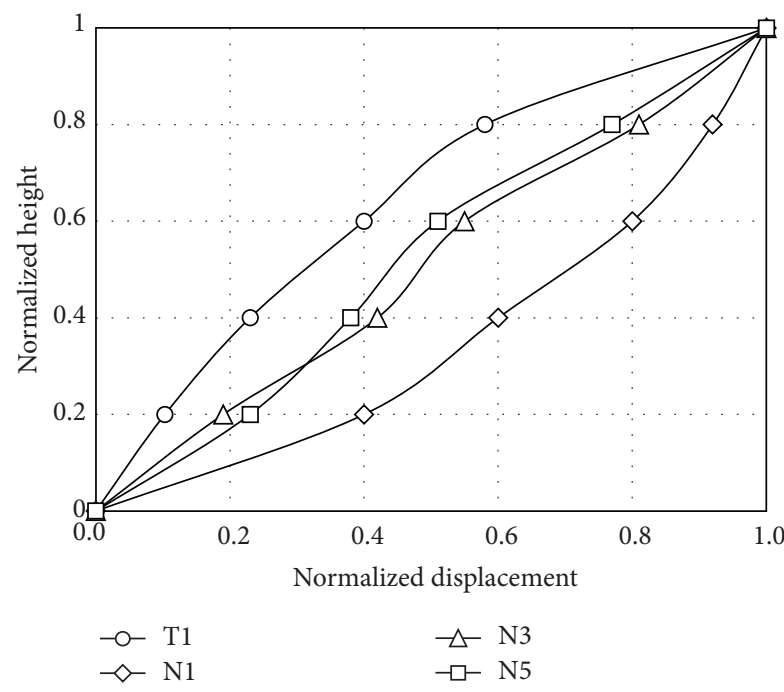

(a)

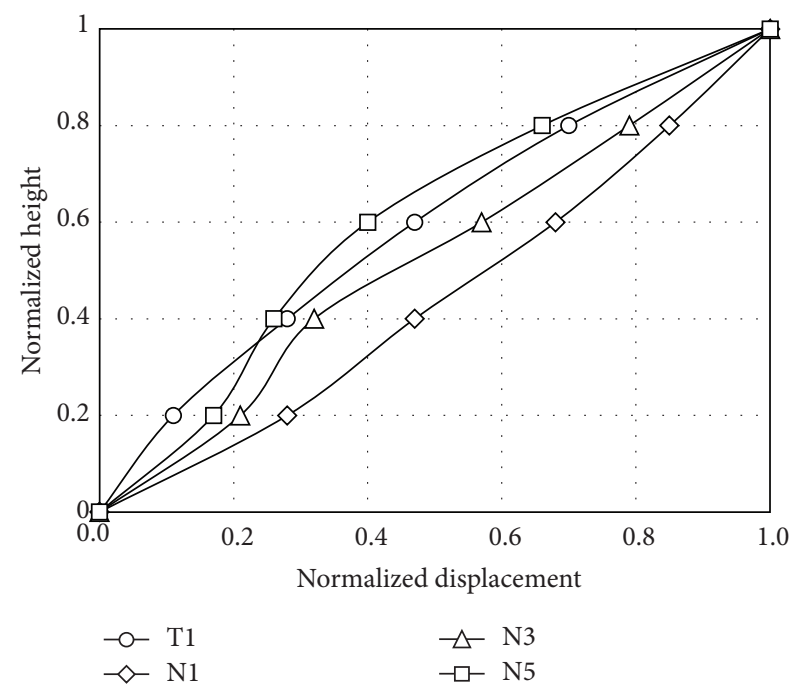

(b)

FIGURE 11: Mode shapes of the building: (a) N-S direction, (b) E-W direction.

\section{Conclusions}

This paper presents vibration analysis of a steel-frame building considering the infill panels' effect through experimental, numerical, and analytical approaches. In order to extract the actual natural frequencies of the building various steady state forced and ambient vibration experimental tests were carried out. It was found that the results of two methods meaning the forced and ambient vibration are the same. In addition, a set of appropriate tests were carried out to realize the compressive and shear strength of the masonry materials of the infill panels. It was observed that the materials are not in good condition and this old building needs to be rehabilitated.

A set of approximate formulas were proposed for free vibration analysis of steel structures with various structural systems, where the frame is idealized as prismatic cantilever flexural-shear beam. In the proposed technique, soilstructure interaction is considered as axial and torsional springs whose potential energy is formulated and incorporated into overall potential energy of the structure.

Moreover, a set of three-dimensional finite element models of the building were provided. In these models main structural systems are modeled by "beam" elements while the infill panels are simulated macromechanically by either continuum elements or equivalent struts.
It was found that modeling infill panels has significant effect on vibration characteristics of the structures and neglecting their effects can leads to errors about 35\%-45\% in natural frequencies. Considering soil-structure interaction leads to more flexibility in the system and decreases frequency of system. Generally, modeling infill panels by continuum elements lead to higher frequencies and decrease the percentage of the errors between the finite element model and experimental tests. It was concluded that using detailed finite element model of the structure, modeling infill panels using shell elements, and also considering the soil-structureinteraction may leads to more accurate result.

It was shown that the proposed approximate formulas have good capability in estimation of the natural frequency of steel structures. They can be used for computing the frequency of various structural systems by less computational efforts. In the present study, there is only $1.5 \%-2.5 \%$ error when using the approximate formulas compared to the forced vibration test. Also, it was shown that the codified proposed formulas have a close estimation to the test results and lead to errors of about $2 \%-12 \%$ in considered building.

\section{Conflict of Interests}

The authors declare that there is no conflict of interests regarding the publication of this paper. 


\section{References}

[1] M. N. Fardis, S. N. Bousias, G. Franchioni, and T. B. Panagiotakos, "Seismic response and design of RC structures with plan-eccentric masonry infills," Earthquake Engineering and Structural Dynamics, vol. 28, no. 2, pp. 173-191, 1999.

[2] K. A. Ghassan, Non-ductile behavior of reinforced concrete frames with masonry infill panels subjected to in-plane loading [Ph.D. thesis], University of Illinois at Chicago, USA, Chicago, Ill, USA, 1998.

[3] A. A. Chaker and A. Cherifati, "Influence of masonry infill panels on the vibration and stiffness characteristics of RC frame buildings," Earthquake Engineering \& Structural Dynamics, vol. 28, no. 9, pp. 1061-1065, 1999.

[4] S. Sattar, Influence of masonry infill walls and other building characteristics on seismic collapse of concrete frame buildings [Ph.D. thesis], University of Colorado, Boulder, Colo, USA, 2013.

[5] P. B. Shing, H. R. Lofti, A. Barzegarmehrabi, and J. Bunner, "Finite element analysis of shear resistance of masonry wall panels with and without confining frames," in Proceedings of the 10th World Conference on Earthquake Engineering, pp. 25812586, A. A. Balkema, Rotterdam, The Netherlands, 1992.

[6] M. Dhanasekar and A. W. Page, "Influence of brick masonry infill properties on the behaviour of infilled frames," Proceedings of the Institution of Civil Engineers, vol. 81, no. 2, pp. 593-605, 1986.

[7] T. C. Liauw and C. Q. Lo, "Multibay infilled frames without shear connectors," ACI Structural Journal, vol. 85, no. 4, pp. 423428, 1988.

[8] A. B. Mehrabi and P. B. Shing, "Finite element modeling of masonry-infilled RC frames," Journal of Structural Engineering, vol. 123, no. 5, pp. 604-613, 1997.

[9] H. R. Lotfi and P. B. Shing, "An appraisal of smeared crack models for masonry shear wall analysis," Computers and Structures, vol. 41, no. 3, pp. 413-425, 1991.

[10] T. B. Panagiotakos and M. N. Fardis, "Seismic response of infilled RC frames structures," in Proceedings of the 11th World Conference on Earthquake Engineering, Paper No. 225, Acapulco, Mexico, 1996.

[11] G. Uva, F. Porco, and A. Fiore, "Appraisal of masonry infill walls effect in the seismic response of RC framed buildings: a case study," Engineering Structures, vol. 34, no. 1, pp. 514-526, 2012.

[12] D. Celarec, P. Ricci, and M. Dolšek, "The sensitivity of seismic response parameters to the uncertain modelling variables of masonry-infilled reinforced concrete frames," Engineering Structures, vol. 35, pp. 165-177, 2012.

[13] D. Celarec and M. Dolšek, "The impact of modelling uncertainties on the seismic performance assessment of reinforced concrete frame buildings," Engineering Structures, vol. 52, pp. 340-354, 2013.

[14] M. Holmes, "Steel frame with brickwork and concrete infilling," ICE Proceedings, vol. 19, pp. 473-478, 1961.

[15] B. Stafford-Smith, "Lateral stiffness of infilled frames," Journal of Structural Division, vol. 88, pp. 183-199, 1962.

[16] B. Stafford-Smith and C. Carter, "A method of analysis for infilled frames," ICE Proceedings, vol. 44, pp. 31-48, 1969.

[17] R. J. Mainstone and G. A. Weeks, "The influence of a bounding frame on the racking stiffness and strengths of brick walls," in Proceedings of the 2nd International Brick Masonry Conference (SIBMAC '70), Building Research Station, England, UK, 1970.
[18] R. J. Mainstone, "On the stiffness and strengths of infilled frames," ICE Proceedings, vol. 49, no. 2, p. 230, 1971.

[19] R. E. Klingner and V. V. Bertero, "Earthquake resistance of infilled frames," Journal of the Structural Division, vol. 104, no. 6, pp. 973-989, 1978.

[20] L. Te-Chang and K. Kwok-Hung, "Nonlinear behaviour of nonintegral infilled frames," Computers and Structures, vol. 18, no. 3, pp. 551-560, 1984.

[21] C. A. Syrmakezis and V. Y. Vratsanou, "Influence of infill walls to RC frames Response," in Proceedings of the 8 th European Conference on Earthquake Engineering (EAEE '86), pp. 47-53, European Association for Earthquake Engineering, Istanbul, Turkey, 1986.

[22] R. Zarnic and M. Tomazevic, "An experimentally obtained method for evaluation of the behavior of masonry infilled RC frames," in Proceedings of the 9th World Conference on Earthquake Engineering, pp. 163-168, 1988.

[23] T. Schmidt, "An approach of modelling masonry infilled frames by the F.E. method and a modified equivalent strut method, Darmstadt Concrete," Annual Journal on Concrete and Concrete Structures, pp. 185-194, 1989.

[24] C. Z. Chrysostomou, Effects of degrading infill walls on the nonlinear seismic response of two-dimensional steel frames [Ph.D. thesis], Cornell University Press, Ithaca, NY, USA, 1991.

[25] A. Saneinejad and B. Hobbs, "Inelastic design of infilled frames," Journal of Structural Engineering, vol. 121, no. 4, pp. 634-650, 1995.

[26] F. J. Crisafulli, Seismic behavior of reinforced concrete structures with masonry infills [Ph.D. thesis], University of Canterbury, Christchurch, New Zealand, 1997.

[27] R. D. Flanagan and R. M. Bennett, "Arching of masonry infilled frames: comparison of analytical methods," Practice Periodical on Structural Design and Construction, vol. 4, no. 3, pp. 105-110, 1999.

[28] W. W. El-Dakhakhni, M. Elgaaly, and A. A. Hamid, “Three-strut model for concrete masonry-infilled steel frames," Journal of Structural Engineering, vol. 129, no. 2, pp. 177-185, 2003.

[29] M. Dolšek and P. Fajfar, "The effect of masonry infills on the seismic response of a four-storey reinforced concrete frame-a deterministic assessment," Engineering Structures, vol. 30, no. 7, pp. 1991-2001, 2008.

[30] D. A. Foutch, Study of the vibration characteristics of two multistory building [Ph.D. thesis], California Institute of Technology, Pasadena, Calif, USA, 1977.

[31] S. K. Jain, "Continuum models for dynamics of buildings," Journal of Engineering Mechanics, vol. 110, no. 12, pp. 1713-1730, 1984.

[32] P. C. Jennings, R. B. Matthiesen, and J. Brent Hoerner, "Forced vibration of a tall steel-frame building," Earthquake Engineering and Structural Dynamics, vol. 1, pp. 107-132, 1972.

[33] D. S. A. Foutch, "The vibrational characteristics of a twelvestorey steel frame building," Earthquake Engineering and Structural Dynamics, vol. 6, no. 3, pp. 265-294, 1978.

[34] M. D. Trifunac, "Comparisons between ambient and forced vibration experiments," Earthquake Engineering and Structural Dynamics, vol. 1, no. 2, pp. 133-150, 1972.

[35] N. M. Auciello and G. Nolè, "Vibrations of a cantilever tapered beam with varying section properties and carrying a mass at the free end," Journal of Sound and Vibration, vol. 214, no. 1, pp. 105-118, 1998. 
[36] J. Wu and C. Chen, "An exact solution for the natural frequencies and mode shapes of an immersed elastically restrained wedge beam carrying an eccentric tip mass with mass moment of inertia," Journal of Sound and Vibration, vol. 286, no. 3, pp. 549-568, 2005.

[37] D.-W. Chen and J.-S. Wu, "The exact solutions for the natural frequencies and mode shapes of non-uniform beams with multiple spring-mass systems," Journal of Sound and Vibration, vol. 255, no. 2, pp. 299-322, 2003.

[38] Q. S. Li, H. Cao, and G. Li, "Analysis of free vibrations of tall buildings," Journal of Engineering Mechanics, vol. 120, no. 9, pp. 1861-1876, 1994.

[39] H. Lin and S. C. Chang, "Free vibration analysis of multi-span beams with intermediate flexible constraints," Journal of Sound and Vibration, vol. 281, no. 1-2, pp. 155-169, 2005.

[40] R. D. Firouz-Abadi, H. Haddadpour, and A. B. Novinzadeh, "An asymptotic solution to transverse free vibrations of variablesection beams," Journal of Sound and Vibration, vol. 304, no. 3-5, pp. 530-540, 2007.

[41] S. A. Sina, H. M. Navazi, and H. Haddadpour, "An analytical method for free vibration analysis of functionally graded beams," Materials and Design, vol. 30, no. 3, pp. 741-747, 2009.

[42] E. Carrera, M. Petrolo, and P. Nali, "Unified formulation applied to free vibrations finite element analysis of beams with arbitrary section," Shock and Vibration, vol. 18, no. 3, pp. 485-502, 2011.

[43] H. Ghasemzadeh, H. Rahmani-Samani, and M. Mirtaheri, "Vibration analysis of steel structures including the effect of panel zone flexibility based on the energy method," Earthquake Engineering and Engineering Vibration, vol. 12, pp. 587-598, 2013.

[44] B. Akgöz and Ö. Civalek, "Free vibration analysis of axially functionally graded tapered Bernoulli-Euler microbeams based on the modified couple stress theory," Composite Structures, vol. 98, pp. 314-322, 2013.

[45] X.-F. Li, Y.-A. Kang, and J.-X. Wu, "Exact frequency equations of free vibration of exponentially functionally graded beams," Applied Acoustics, vol. 74, no. 3, pp. 413-420, 2013.

[46] Instruction for Seismic Rehabilitation of Existing Buildings, Code No. 360, Management and Planning Organization (Office of Deputy for Technical Affairs), 2007.

[47] A. K. Chopra, Dynamics of Structures, Prentice Hall, Englewood Cliffs, NJ, USA, 1995.

[48] ASCE-FEMA, "Pre-standard and commentary for the seismic rehabilitation of buildings," FEMA 356, 2000. 

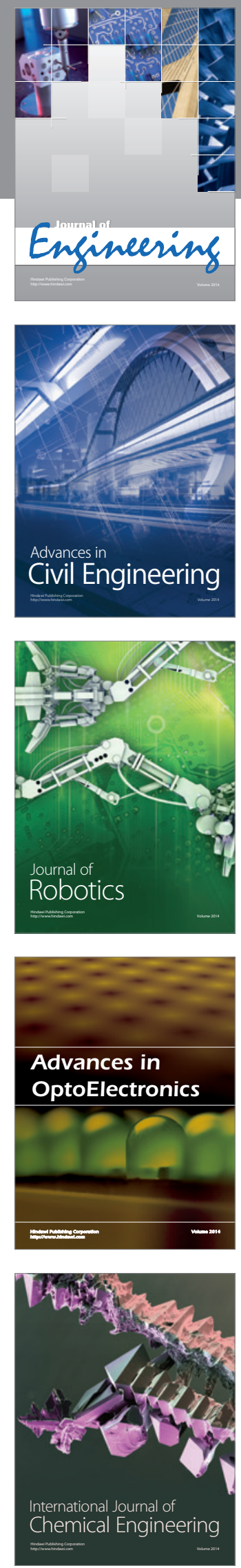

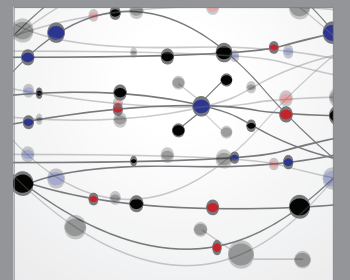

The Scientific World Journal
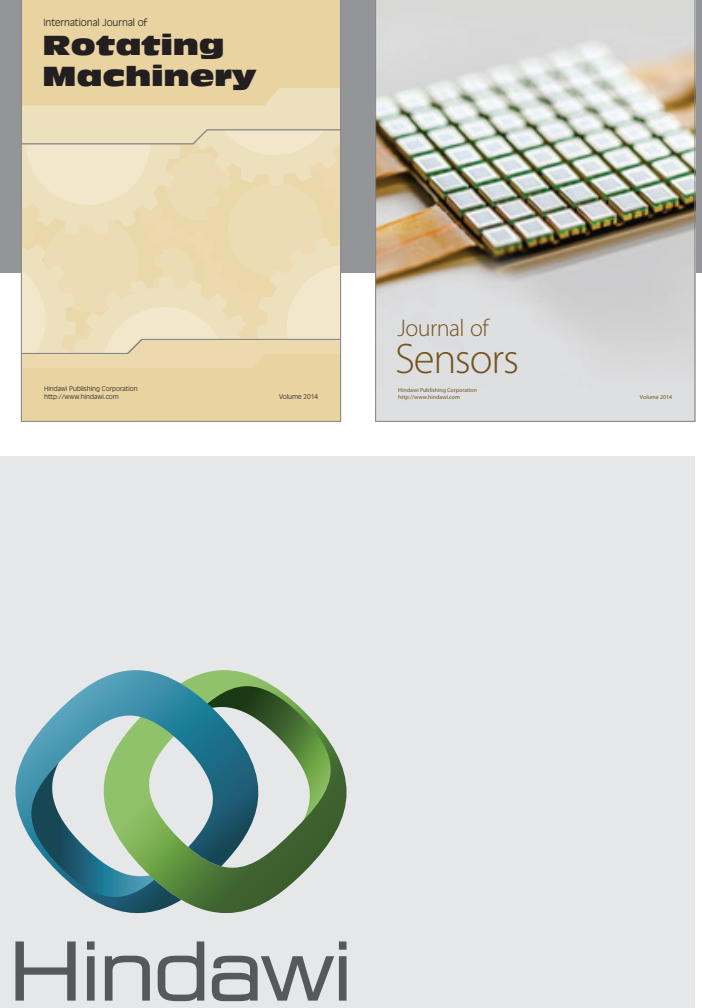

Submit your manuscripts at http://www.hindawi.com
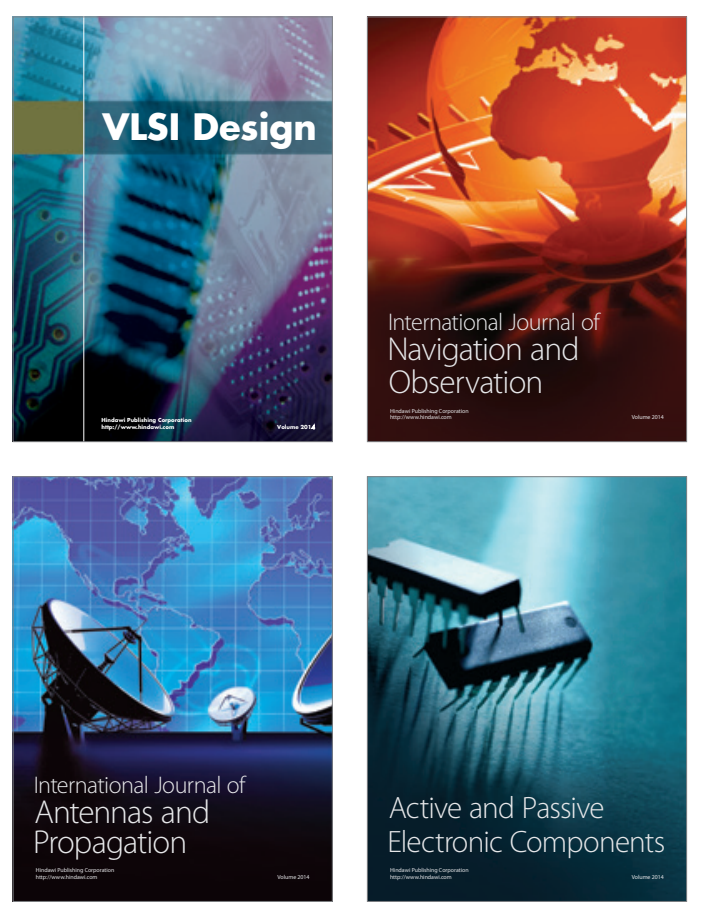
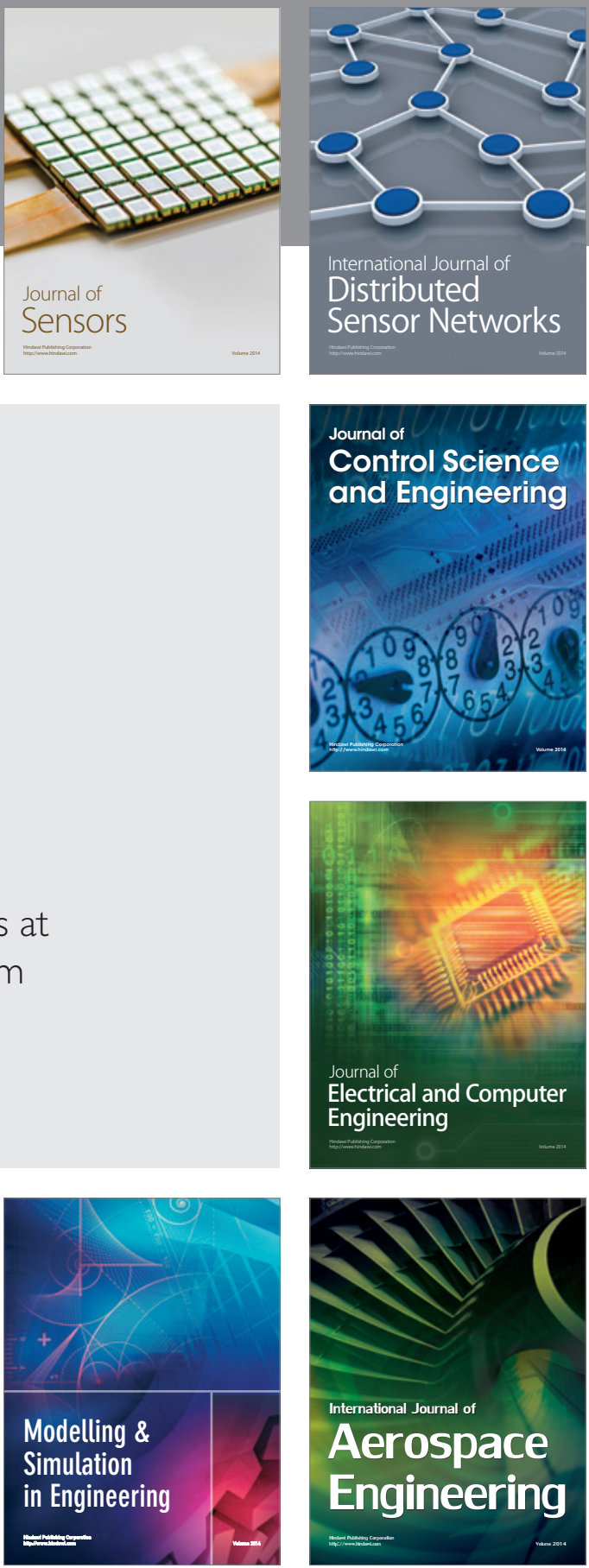

Journal of

Control Science

and Engineering
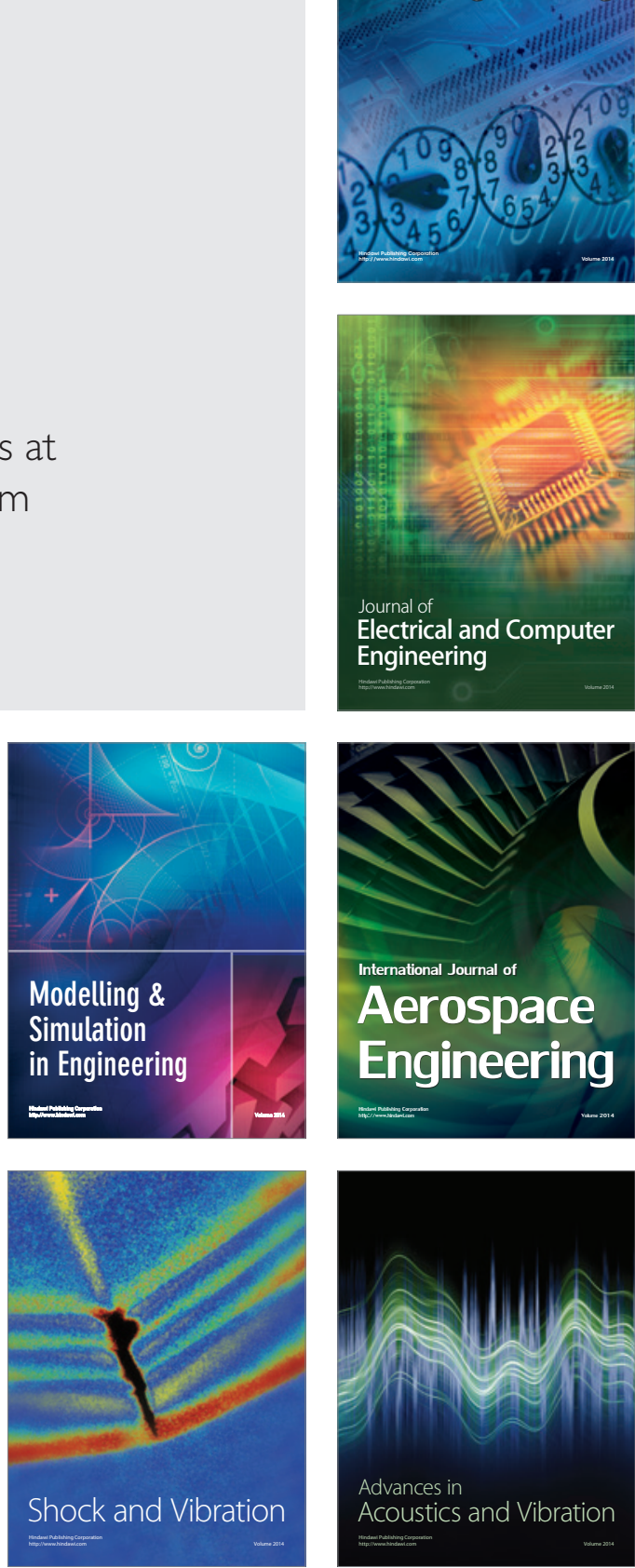